\title{
O PROGRAMA MINHA CASA MINHA VIDA E SEUS RESULTADOS FORMAIS EM UBERABA (MG): RESIDENCIAL TANCREDO NEVES
}

\author{
PROGRAM "MY HOUSE MY LIFE" AND ITS FORMAL RESULTS IN UBERABA (MG): \\ RESIDENTIAL TANCREDO NEVES
}

\author{
Carmem Silvia Maluf* \\ Verônica García Donoso** \\ Mariana Valicente Moreira** \\ João Batista de Oliveira Junior****
}

\section{RESUMO}

Este artigo propõe a discussão do Programa Minha Casa Minha Vida, suas consequências e transformações cíclicas no espaço urbano, com foco na análise da morfologia urbana resultante do loteamento residencial Tancredo Neves, localizado no município de Uberaba (MG). O mesmo possui algumas características únicas, diferenciando-se dos demais conjuntos, desde o público até a utilização imprópria da Área de Preservação Permanente (APP) por parte dos moradores. Os resultados obtidos por esta análise reforçam a importância do poder público na promoção da habitação, identifica a recorrente reprodutibilidade de modelos habitacionais, além de mostrar como essa proliferação de unidades habitacionais impacta a morfologia urbana, trazendo consigo questionáveis consequências para a paisagem.

Palavras-chave: Programa Minha Casa Minha Vida. Morfologia urbana. Habitação social. Forma urbana. Produção do espaço.

\begin{abstract}
This article proposes the discussion of the housing policy "Minha Casa Minha Vida" ("My House My Life"), its consequences and recurrent transformations for urban space, with focus in the analysis of the urban morphology resulting from Tancredo Neves residential subdivision, located in the municipality of Uberaba (MG, Brasil). This social housing has some single features, differing of other social housing, since the public intended to misuse of Permanent Preservation Areas (APP) by the residents. The results of this analysis reinforce the importance of government in promoting housing, and identifies the recurrent reproducibility of
\end{abstract}

\footnotetext{
* $\quad$ Arquiteta e Urbanista, doutora pela Faculdade de Arquitetura e Urbanismo da Universidade de São Paulo (FAUUSP). Professora da Universidade de Uberaba (Uniube). Pesquisadora do Grupo de Pesquisa do Ambiente Construído (GPAC). Rua Cândida Mendonça Bilharinho, 308, Mercês, 38060-150, Uberaba, MG, Brasil. carmem.maluf@uniube.br

** Arquiteta e Urbanista, mestre pela Faculdade de Arquitetura e Urbanismo da Universidade de São Paulo (FAUUSP). Professora da Universidade de Uberaba (Uniube). Pesquisadora doutoranda do Laboratório Quadros do Paisagismo no Brasil, da Faculdade de Arquitetura e Urbanismo da Universidade de São Paulo (LabQuapá/ FAUUSP). Avenida Eliseu de Almeida, 2.046, ap. 102 C, Instituto de Previdência, 05533-000, São Paulo, SP, Brasil. veronica.donoso@usp.br

*** Graduanda em Arquitetura e Urbanismo pela Universidade de Uberaba (Uniube). Aluna de Iniciação Científica do Grupo de Pesquisa do Ambiente Construído (GPAC). Rua Prof. Ver. Murilo Pacheco de Menezes, 12, Residencial Mário Franco, 38046-365, Uberaba, MG, Brasil. mvalicente@gmail.com

**** Graduando em Arquitetura e Urbanismo pela Universidade de Uberaba (Uniube). Aluno de Iniciação Científica do Grupo de Pesquisa do Ambiente Construído (GPAC). Rua Ceará, 1.630, bloco 1, ap. 401, Mercês, 38050-450, Uberaba, MG, Brasil.

juaojr25@gmail.com
} 
housing models, and show how this proliferation of housing units impacts on urban morphology, bringing with questionable consequences for the landscape.

Keywords: Housing policy "Minha Casa Minha Vida". Urban morphology. Social housing. Urban form. Production of space.

\section{INTRODUÇÃO: NOTAS GERAIS}

O Programa Minha Casa Minha Vida (PMCMV), criado em 2008, possui como objetivo tentar suprir o grande déficit de moradia que o Brasil acumulou ao longo da sua história. $\bigcirc$ programa é uma tentativa de atender às necessidades habitacionais da população, atingindo diversas classes econômicas, através de subsídios públicos. Segundo Donoso, Maluf e Moreira (2012), o sistema de subsídios alimenta o mercado construtivo, que, através dessa viabilidade financeira, acaba tornando possível o acesso à moradia própria.

Diante desse novo modelo, é essencial entender como o mercado se relaciona com o mesmo e como a cidade e sua morfologia são impactadas com essa nova leva de residências.

O PMCMV encontra-se em sua segunda edição, havendo diferenças importantes entre o PMCMV 1 e o PMCMV 2, como alterações na metragem mínima da área construída, no valor da moradia, previsão de melhoria na acessibilidade. Outra mudança importante é que, na segunda fase do programa, as mulheres chefes de família poderão dar entrada no programa independentemente de seu estado civil.

O programa funciona com a união entre os agentes financiadores e construtoras, ambos sob a supervisão das exigências técnicas do PMCMV, proposto pelo governo federal. $\bigcirc$ município não possui responsabilidade pelo resultado formal do projeto, sendo a responsabilidade arquitetônica e urbanística depositada no agente financiador e construtor.

Com base no funcionamento do programa e em seus maiores responsáveis pela realização e execução, o fator econômico ganha mais espaço, definindo localização e soluções projetuais. Com fatores financeiros priorizados em relação à habitação, temos, como consequência, partidos projetuais pensados em função do custo da terra, unidades com áreas reduzidas e infraestrutura mínima, justificando, assim, a localização periférica de grande parte dos conjuntos habitacionais. Segundo Bonduki (2009, p. 113):

El suelo urbanizado, provisto de servicios, equipamientos e infraestructura, se hizo cada vez más caro, desplazando a los que no tenían recursos a lugares cada vez más distantes, precários y peligrosos y a laocupación irregular. Este creciente proceso muestra la ausência de una política fundiária articulada com las políticas habitacional y urbanística, em los diferentes niveles de gobierno en Brasil.

No artigo "Do Projeto Moradia ao Programa Minha Casa Minha Vida", o autor comenta: 
A localização dos empreendimentos poderá ser inadequada, em áreas carentes de emprego, infraestrutura e equipamentos, correndo o risco, ainda, de gerar impactos negativos como a elevação do preço da terra, que representaria a transferência do subsídio para a especulação imobiliária, desvirtuando os propósitos do programa (BONDUKl, 2009b, p. 13)

A consequência desse ato é a necessidade de maiores investimentos públicos em tais regiões, devido, em geral, à falta de infraestrutura nessas novas áreas de expansão urbana, de maneira a suprir a carência de abastecimento de água, esgoto, vias e transportes públicos, equipamentos de saúde, educação e lazer. Os habitantes de áreas periféricas, por sua vez, sofrem com o maior tempo de deslocamento e os custos do dia a dia, refletindo maior dificuldade para a realização de atividades rotineiras, como trabalho, saúde e lazer.

Diante da grande dimensão e importância do PMCMV, é essencial encará-lo como fator de alteração e definição da morfologia urbana. Por funcionar associado ao setor privado, o PMCMV possui grande dependência do capital, visando, no final, ao lucro das empresas privadas que o apoiam e implementam. Essa lógica é um revés para a qualidade das habitações e dos espaços que as circundam, que recebem diretrizes de menores custos e massificação em sua produção.

Com base nesse pensamento padrão e na consequente universalização dos interesses financeiros de quem executa o PMCMV, os projetos são comumente reproduzidos em série, não somente no perímetro de um município, mas também além das divisas estaduais, fazendo com que essa padronização atinja regiões diversas.

\section{O PROGRAMA MINHA CASA MINHA VIDA EM UBERABA (MG)}

A cidade de Uberaba cresceu sem questionar a necessidade de renovação, intervenção e criação de novos Sistemas de Espaços Livres. A carência aumenta no sentido centro/periferia, que se multiplica exponencialmente, acompanhada da ausência de infraestrutura e equipamentos urbanos. Sucessivos loteamentos populares espraiaram-se em anéis ao redor do núcleo central, em quase sua totalidade, repetindo modelos ultrapassados de ocupação do espaço urbano, nos quais se prioriza o promotor do empreendimento em detrimento do usuário final.

O PMCMV potencializa o crescimento linear periférico na cidade de Uberaba. O valor do solo associado ao potencial do mercado imobiliário local, à carência de moradia e ao sonho eterno da casa própria, apontam para a ocupação horizontal a perder de vista, estendendo-se pela paisagem há pouco tempo rural. Não mais impactante que a atividade agropecuária que a precedeu, esse novo modelo de exploração do solo (o da habitação de interesse social pelas empreiteiras) aproxima-se das matas ciliares remanescentes, sobreviventes dos braços dos pivôs de irrigação.

Focando na análise do PMCMV em Uberaba (MG), percebemos a padronização do pensamento para implantar os loteamentos no perímetro urbano. Essa padronização 
leva em conta os preços da terra, justificando com isso a localização periférica dos conjuntos habitacionais. As implicações dessa atitude, além da consequente carência de infraestrutura comprometendo diretamente os moradores, é também o crescimento fragmentado e desorganizado da cidade, com enormes vazios intrabairros que, com o passar do tempo, com o desenvolvimento econômico da região através de investimentos privados, se tornarão, certamente, áreas de especulação imobiliária.

No caso dos conjuntos habitacionais formados para a faixa 1 do programa, em Uberaba (MG), a tipologia de residências e sua distribuição pelo espaço urbano se assemelham em vários casos, como nos Conjuntos Girassol, Copacabana e Manoel Mendes. Essa semelhança é definida não pelo tamanho das residências, pois esse já é imposto pelo PMCMV, mas pela sua distribuição no lote, infraestrutura e desenho urbano dos conjuntos.

Ainda apoiado nesse fator de redução de custos, temos, correlacionados, os conceitos de matéria-prima e tecnologia, que também se incluem na mesma premissa, racionalizando a produção para o aumento de lucros e produtividade, deixando em segundo plano a questão da qualidade da habitação e de seu entorno, infraestrutura e desenho urbano. Somente dessa forma o projeto se torna vantajoso para as construtoras que o executam, ao mesmo tempo em que se torna acessível para a população.

É importante ressaltar que o PMCMV não propõe diretrizes e nem reserva recursos destinados à melhoria na infraestrutura e equipamentos urbanos. O programa apenas tem como partido que áreas com infraestrutura básica, transporte e serviços seriam priorizadas na escolha da região de implantação dos projetos, todavia, percebemos que na maioria dos exemplos espalhados no Brasil isso não ocorre.

Partindo para uma escala mais próxima do projeto, as tipologias de residência variam de acordo com a faixa a que atendem, além de possuírem soluções verticais e horizontais. Em cidades como Uberaba, por haver maior disponibilidade de terra, não existe a necessidade de verticalização. Sendo assim, o projeto pode apropriar-se de mais área.

\section{O RESIDENCIAL PRESIDENTE TANCREDO NEVES}

O Residencial Presidente Tancredo Neves é um loteamento implantado em terreno doado pelo $4^{\circ}$ Batalhão da Polícia Militar, com auxílio do Governo do Estado de Minas Gerais, da Prefeitura de Uberaba e da Companhia Habitacional do Vale do Rio Grande (Cohagra), sendo construído pela Construtora Centro Minas (CCM).

A área total loteada é de $370.708,00 \mathrm{~m}^{2}$, sendo $158.298,96 \mathrm{~m}^{2}$ representando $42,7 \%$, destinado aos lotes. A área pública tem total de 212.409,04 m² (57,3\%).

O residencial destinou-se a servidores públicos municipais e estaduais, membros das Polícias Militar e Civil e ao grupo do Corpo de Bombeiros, como benefício pelo seu esforço em prol da comunidade e pela necessidade de um lugar próximo do local de trabalho dos servidores, sendo indispensável ter renda entre 3 a 6 salários mínimos. 
A construção do residencial iniciou-se em 2006, passando por cinco etapas até a sua conclusão, em 2012. No total, foram entregues 592 habitações. Ao longo de sua extensão territorial, percebem-se dois tipos de habitações:

- tipologia A: com 82,75 m², implantada em lotes de 12×30 m e 10×25 m, possuindo 3 quartos (sendo um suíte), 1 sala/jantar, 1 cozinha, 2 banheiros e área de serviço;

- tipologia B: com 53,4 m², configurada em lotes de 10x25m, contendo 2 quartos, 1 sala, 1 cozinha/jantar, 1 banheiro e 1 área de serviço.

As habitações são entregues apenas com os muros laterais e posteriores e solo não pavimentado. Suas fundações são executadas em sistema radier de concreto armado e a laje pré-moldada possui características de uma "laje de forro/cobertura". Podemos perceber os sistemas construtivos na figura 1.

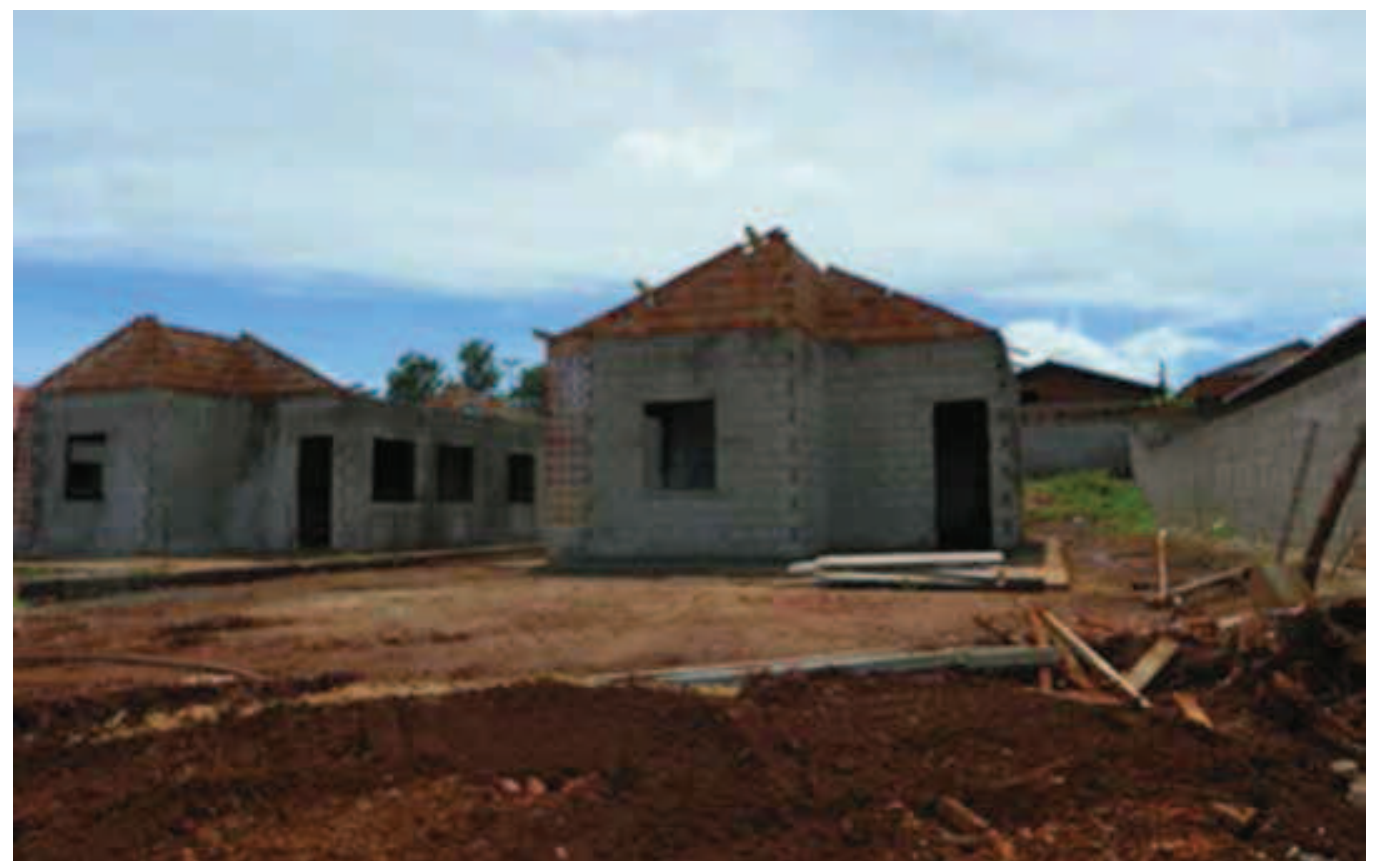

Figura 1 Processo construtivo do Conjunto Tancredo Neves em Uberaba (MG). Foto: Mariana Valicente Moreira - 26 fev. 2011.

As áreas (triangulares) destinadas ao uso institucional no residencial, reservadas por lei para implantação de equipamentos urbanos essenciais ao desenvolvimento e à sobrevivência das comunidades, serão destinadas a serviços de saúde, à educação e segurança, quando forem executados pela prefeitura.

Mesmo as áreas definidas no projeto como verdes, também legalmente exigidas para aprovação desses empreendimentos, foram deixadas nas extremidades das quadras, próximas ao córrego e à sua Área de Preservação Permanente (APP). Essa prática se dá em função da dificuldade de ocupação das áreas próximas às APPs devido à 
topografia acidentada, o que significa que nenhuma das áreas livres - que deveriam receber tratamento por parte do poder público e serem transformadas em praças -, nesse empreendimento, terá significado real e direto para a população.

A APP existente no local deveria manter-se conservada conforme a legislação ambiental pertinente. Todavia, com a presença de uma APP circundando a área habitacional, muitas dessas áreas sofreram agressões incontáveis durante o processo de implementação do empreendimento do PMCMV e dificilmente conseguirão recuperar-se. A ocupação de suas franjas como canteiro de obras, estacionamento de veículos e máquinas, assim como o pisoteio diário pelos operários das obras, foram capazes de eliminar parte da vegetação rasteira comum na área do cerrado, como mostra a figura 2.

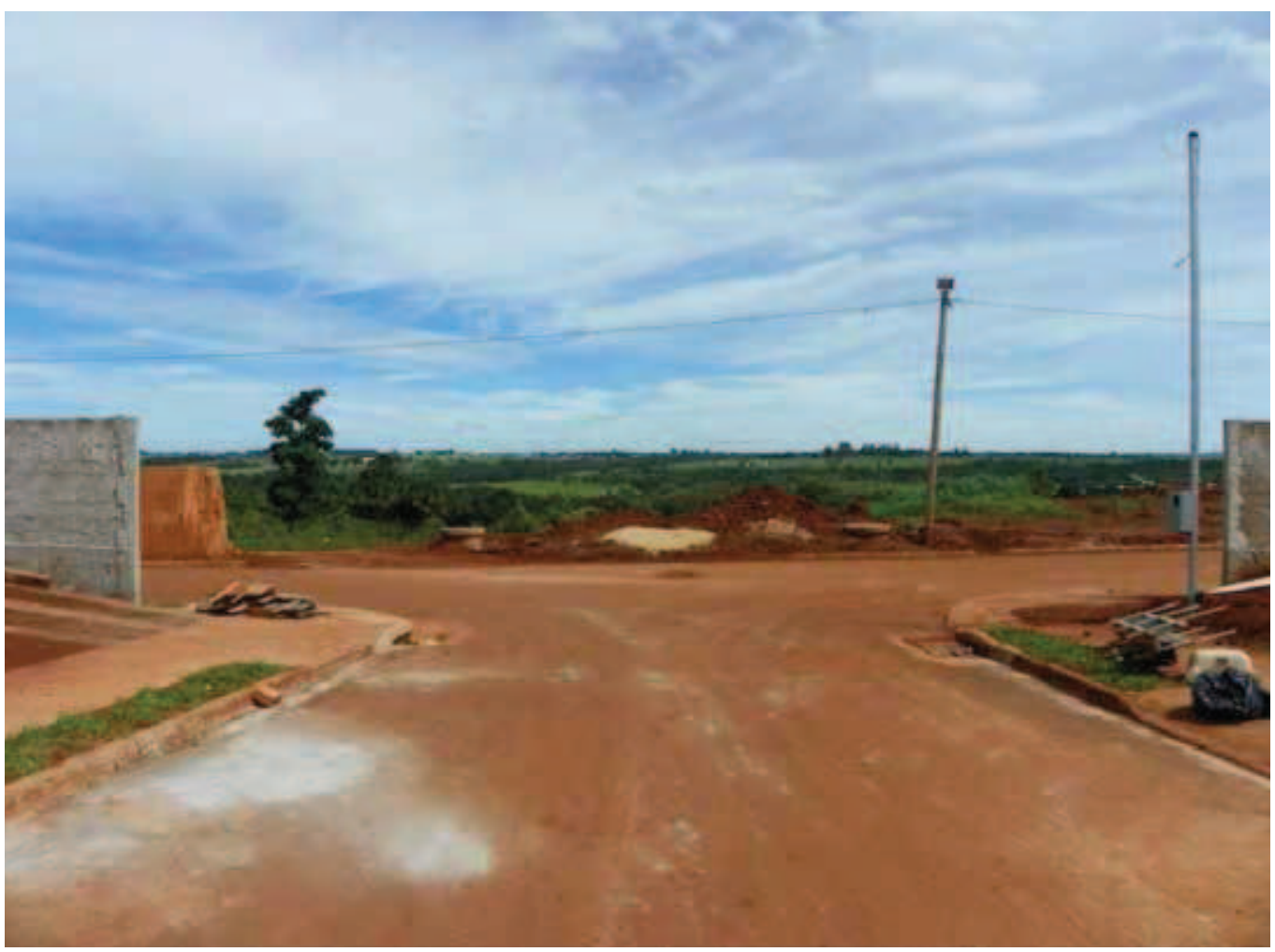

Figura 2 Vista para a APP do conjunto Tancredo Neves. Foto: Mariana Valicente Moreira - 26 fev. 2011.

Outro fator a ser considerado em relação às áreas livres no loteamento é a ausência de áreas destinadas ao lazer. Devido a tal carência, a apropriação da APP pela população, que a assume como parte integrante do seu cotidiano, acaba não sendo tão respeitosa. A APP acaba se tornando extensão da área residencial (figura 3) devido ao desconhecimento da legislação por parte dos moradores e pela ausência de infraestrutura cedida ao loteamento pelas construtoras.

O Sistema de Espaços Livres (SEL) públicos se resume às vias locais, único espaço em que ainda poderia acontecer algum tipo de relação entre a população e a cidade, e que, por si só, não garante qualidade ao espaço. 
A construção dos muros frontais isola ainda mais a capacidade de interação entre o espaço público e privado, fazendo com que as ruas não tenham, necessariamente, garantia de que efetivamente serão utilizados pela população como áreas de lazer, restringindo-se a espaços de fluxo para as atividades do dia a dia.

Outra questão recorrente no desenho dos loteamentos vinculados ao PMCMV é a disposição dos lotes na quadra e das construções nos lotes, que acabam por deixar uma rua com "fachadas cegas", devido ao fato de os moradores voltarem suas fachadas frontais sempre para a mesma rua, como exemplifica a figura 4.

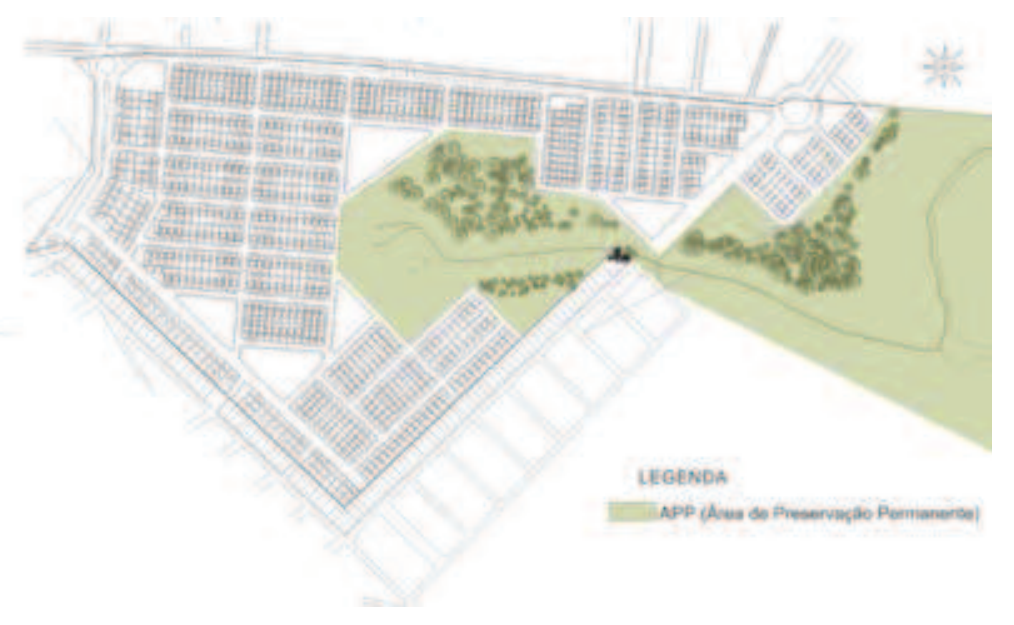

Figura 3 Planta do loteamento Tancredo Neves, com APP demarcada.

Fonte: Grafismo de Mariana Valicente Moreira sobre fontes diversas - 11 jul. 2013.

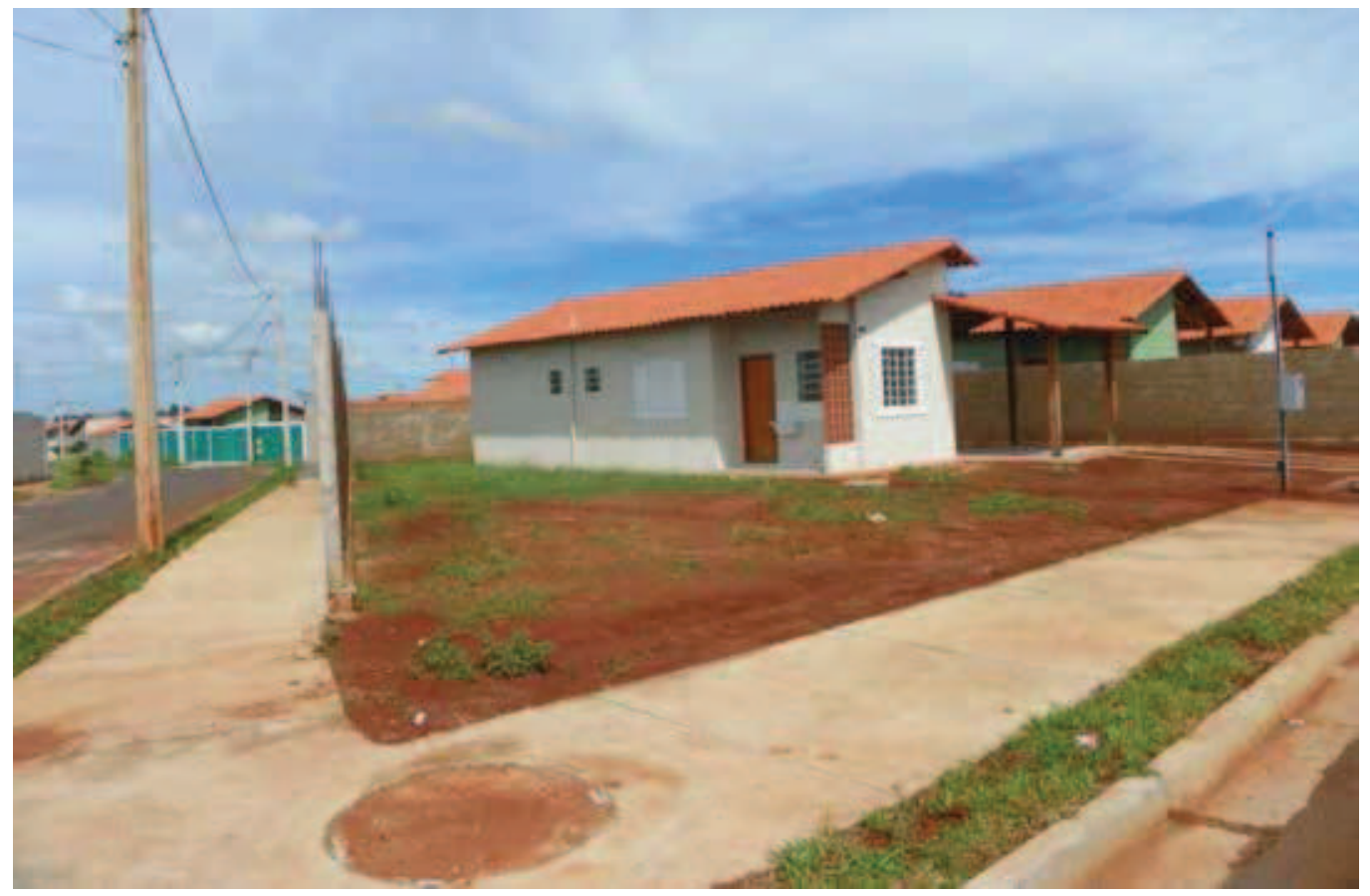

Figura 4 Divisão de lote de esquina no Conjunto Tancredo Neves, em Uberaba (MG).

Foto: Mariana Valicente Moreira - 26 fev. 2011. 
Essas ruas, que recebem as fachadas laterais, geralmente sem aberturas, muradas e, consequentemente, sem geração de fluxo, acabam tornando-se ruas sem grande apropriação. Essa disposição dos lotes e da hierarquia de importância das ruas pode ser notada na figura 5 .

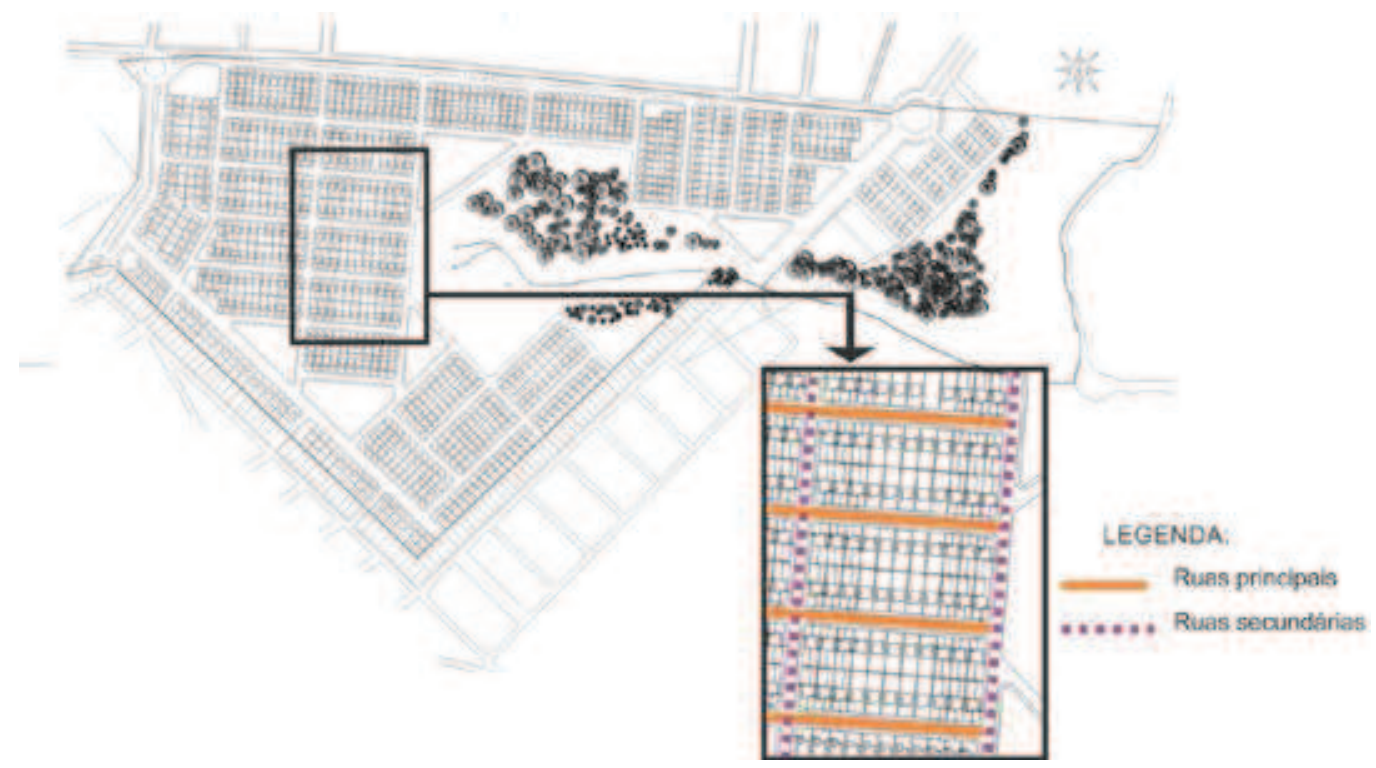

Figura 5 Planta do loteamento Tancredo Neves.

Fonte: Grafismo de Mariana Valicente Moreira sobre fontes diversas - 11 jul. 2013.

Ao longo dos anos, vários termos foram criados para o traçado ortogonal, sendo também conhecido por tabuleiro, plano em xadrez, grelha. Os mesmos possuem uma função para identificar as linhas que lembram uma forma elementar de compor ruas e edifícios, criando, assim, um dos mais antigos desenhos morfológicos do traçado urbano. Extensos loteamentos pontilhados de unidades habitacionais sem nenhuma qualidade, distribuídas em longos quarteirões consecutivos, separados pelo sistema viário (rua e passeios) legal mínimo, contribuem para uma paisagem homogênea e monótona.

O mesmo ocorre no Conjunto Habitacional Presidente Tancredo Neves, produzido em grande escala, de forma rápida, ortogonal, gerando maior celeridade no uso do solo. Os lotes, legalmente mínimos, são rapidamente murados e ocupados por ampliações da unidade original dependendo da capacidade econômica do comprador.

Todavia, ao mesmo tempo em que se produziram as habitações em massa, a identidade das moradias foi deixada à parte. Com área extremamente reduzida e programa exíguo, a unidade habitacional não atende às reais necessidades das famílias. Isso, associado à falta de fechamento frontal do lote, leva a população a intervir rapidamente na unidade recém-recebida, expandindo-a sobre a área remanescente intralote, construindo lavanderias, garagens e levantando seus muros. A necessidade de um programa de moradia além da oferecida pelo PMCMV faz com que o espaço livre no interior do lote desapareça rapidamente. Dessa forma, nota-se ao longo da 
malha a variedade de fachadas, sendo normal o ato da customização dos muros por parte dos moradores.

As ruas de todo o conjunto possuem 8 metros de largura, sendo todas pavimentadas. Compondo os eixos das vias há a adição de 2 metros de calçada cimentada de ambos os lados, onde são notáveis os poucos pontos de acesso para portadores de necessidades especiais. Nessa configuração, percebe-se a carência de espaços livres públicos e os estudos constataram a necessidade da população em apropriar-se, de alguma maneira, do espaço público e privado do conjunto habitacional, seja pela utilização da área de preservação permanente, como já colocado, seja pela customização dos lotes e das habitações por parte dos moradores, de maneira a dar alguma identidade ao bairro.

O estudo do Conjunto Habitacional Presidente Tancredo Neves mostra mais um dos casos brasileiros de resultados formais questionáveis do PMCMV. A falta de qualidade urbana dos conjuntos criados é preocupante, resultado de uma produção em massa que prioriza a quantidade em detrimento da qualidade. No entanto, o PMCMV ganha importância urbana por ser acessível à população de baixa renda, em detrimento do seu fator despojado de reformulação do espaço e, por consequência, dos fatores econômicos subjugados ao programa, que acabam por determinar uma notória continuidade na baixa qualidade de formulação de desenho urbano. A manutenção desse baixo padrão se estende ao longo da história da habitação social justamente por haver interesses econômicos sobrepondo-se ao interesse social estruturando a execução do projeto.

\section{CONSIDERAÇÕES}

Os espaços, central ou periférico, contraditórios entre si, detêm sua ordem segundo as estruturas de poder (estatal ou local) responsáveis pela sua organização e pela valorização do lugar.

A elite e a classe média têm, na produção do espaço pelo Estado, a garantia da manutenção de seu modelo de vida, a valorização de seus imóveis, a organização de seus lugares, a sustentação de sua riqueza, a segurança no planejamento espacial de seus fluxos e de sua produção. A prática do Estado ratifica-se a serviço das classes economicamente dominantes.

Desse modo, os espaços livres configuram-se como extensões dos jardins das residências da elite e mantêm a harmonia na paisagem. Priorizam, sempre, o qualitativo sobre o quantitativo. O signo do poder, o do domínio, é mantido.

A grande massa de trabalhadores, excluída, vê-se à mercê das políticas econômicas, sejam elas quais forem. Obrigada a viver nos espaços produzidos pelo poder e, portanto, espaços de produção, absorve-os no cotidiano como os únicos possíveis. Aos trabalhadores não são facultados os espaços produzidos para o lazer livre, os espaços de criação. Os espaços públicos gerados no período industrial (BRESCIANI, 1990, p. 98), que serviam para "serenar" os operários nas horas de ócio, foram substituídos, até então, pelos espaços de consumo (campos de futebol, bares, shoppings, feiras), que se 
constituem também em espaços de controle. Privilegiam, portanto, o quantitativo em detrimento do qualitativo.

No PMCMV, nem ao menos esses espaços (os de consumo) são franqueados à população, que é obrigada a longos deslocamentos para acessar quaisquer serviços ou equipamentos.

[Social] space is a [social] product. [...] The more so in view of the further claim that the space thus produced also serves as a tool of thought and of action; that in addition to being a means of production it is also a means of control, and hence of domination, of power; yet that, as such, it escapes in part from those who would make use of it. (LEFEBVRE, 1991, p. 26).

Porém, o ideal de espaço da classe operária é determinado pela ideologia de classe (das classes dominantes), conferindo aos espaços periféricos modelos reproduzidos da área central.

São as contradições entre as relações sociais de produção e de propriedade, entre o domínio dos instrumentos de produção e das forças produtivas, que inserem as diferenças e as contradições no espaço produzido e no seu consumo improdutivo. Nesse caso, inclui-se o espaço (global) também como um instrumento e sua qualidade como produto, pois, na medida em que as classes subalternas não têm a posse desses instrumentos, inclusive dos espaços, não conseguem ter acesso à qualidade, nem ao tempo para usufruí-los. (MALUF, 2008, p. 80)

A propriedade do espaço, à qual a classe menos favorecida tem acesso apenas através da compra de pequenos lotes, não constitui possibilidade de acesso ao espaço de qualidade, uma vez que eles representam apenas um fragmento, incapaz de agregar as características necessárias a essa fruição. Representam uma fração do espaço de produção, do espaço produzido, quantitativo, "global e concebido", sob controle do Estado e das forças produtivas. É um espaço, sobretudo, dominado.

A técnica e as forças de produção deveriam associar-se em busca da produção da qualidade do espaço ("produção consciente do espaço"), libertando a busca pelo quantitativo (produção das coisas) através do desenvolvimento tecnológico, situação esta cada vez mais dissociada do sistema do capital e do modelo de produção do espaço em questão.

\section{REFERÊNCIAS BIBLIOGRÁFICAS}

BONDUKI, Nabil Georges. Política de vivienda e inclusión social en Brasil: revisión histórica y nuevas perspectivas en el gobierno de Lula. In: ESPINOSA, Jaime Erazo (Org.). Inter/secciones urbanas: origen y contexto en América Latina. Quito: FlacsoEcuador/Ministerio de Cultura, 2009, v. 1, p. 95-135.

Do Projeto Moradia ao Programa Minha Casa Minha Vida. Teoria e Debate, v. 82, p. 1, 2009b. São Paulo: Fundação Perseu Abramo, 2009b. 
BRESCIANI, Maria Stella Martins. Londres e Paris no século XIX: o espetáculo da pobreza. 6 ed. São Paulo: Brasiliense, 1990. $127 \mathrm{p}$.

DONOSO, Verônica Garcia. A paisagem e os sistemas de espaços livres na urbanização contemporânea do interior paulista: estudo de caso da área entre São Carlos, Araraquara e Ribeirão Preto. 2011.241 f. Dissertação (Mestrado em Paisagem e Ambiente) - Faculdade de Arquitetura e Urbanismo, Universidade de São Paulo, São Paulo, 2011.

; MALUF, Carmem Silvia; MOREIRA, Mariana Valicente. O Programa Minha Casa Minha Vida em Uberaba (MG): reflexões sobre a dinâmica da produção imobiliária. In: COLÓQUIO QUAPÁ-SEL, 6, 2012, Campo Grande (MS).

LEFEBVRE, Henri. The production of space. Trad.: Donald Nicholson-Smith. Do original La production de l'espace, $4^{a}$ ed. Paris: Éditions Anthropos, 1974, 485 p; Backwell publishing, 1991, 464 p.

MALUF, Carmem Silvia. Espaço, tempo e lugar. Revista PÓS. Programa de Pós-Graduação em Arquitetura e Urbanismo, v. 23, 2008. São Paulo: FAU/USP, p. 70-83. 
Carmem Silvia Maluf, Verônica García Donoso,

Mariana Valicente Moreira e João Batista de Oliveira Junior 